Journal of Research in Nursing

Vol. 2, No. 1, 2016

Print ISSN 2244-2723

University of Cebu

Cebu City, Cebu, Philippines

\title{
Knowledge and Practices on Nutrition in a Community
}

\author{
Rose Delia P. Ocariza \\ Mauro Allan P. Amparado
}

\section{Abstract}

This study assessed the knowledge and practices on nutrition of the mothers with malnourished child/children in Jubay, Liloan, Cebu. The level of knowledge on nutrition was based on the go, grow and glow classification, while nutrition practices was on food selection, food preparation, and feeding. It also described the profile of the respondents in terms of family size, educational attainment, monthly income, and employment status. The key findings were the basis for a proposed action plan.

The study utilized the descriptive-correlational design and used a researcher-made tool, vignettes and follow-up interviews. There were 120 mothers with malnourished child/children (0-5 years old). The statistical treatment used were simple percentage, weighted mean, and chi-square Test of Independence.

The findings showed that the mothers attained high school level education and were employed. Most belonged to a family size with 4-6 household members and a combined monthly income of less than 5,000 Philippine pesos.

Majority of the respondents' level of knowledge on basic food groups was excellent. However, there were challenges on nutrition 
practices in terms of food selection, preparation, and feeding. There was no significant relationship between the level of knowledge on basic food groups and nutrition practices of the respondents.

To overcome nutrition problems in rural areas, nutrition education for mothers should include knowledge and practices that focus on low cost, flavorful, nutritious foods, and ample water supply.

Recommended citation: Ocariza, R. D. P. \& Amparado, M. A. P. (2016). Knowledge and Practices on Nutrition in a Community. Journal of Research in Nursing, 2(1), 60-69. 